Pacific Journal of Mathematics

RADIAL QUASIHARMONIC FUNCTIONS

Rio and CeCILIa Wand 


\title{
RADIAL QUASIHARMONIC FUNCTIONS
}

\author{
Leo Sario and Cecilia Wang
}

A function $s$ on a Riemannian manifold is called quasiharmonic if it satisfies $\Delta s=1$, where $\Delta$ is the Laplace-Beltrami operator $d \delta+\delta d$. Existence of quasiharmonic functions with various boundedness properties has thus far been investigated by means of useful implicit tests. We now ask: Can such functions be formed by direct construction, in a manner accessible to computation if need be?

1. We shall present our approach to the problem in the setup of a Riemannian $N$-ball

$$
B_{\alpha}=\{r<1 \mid d s\}
$$

endowed with the generalized Poincaré metric

$$
d s=\lambda(r)|d x|, \lambda(r)=\left(1-r^{2}\right)^{\alpha}, \alpha \in \boldsymbol{R},
$$

where $r=|x|, x=\left(x^{1}, \cdots, x^{N}\right)$. In [16] we proved that there exist bounded quasiharmonic functions on $B_{\alpha}$ if and only if $\alpha \in(-1,1 /(N-2))$. We shall now show that this in turn is necessary and sufficient for the boundedness of an explicitly constructed function $s(r)$, given in No. 3 below. Thus the boundedness of this single function characterizes the existence of bounded quasiharmonic functions on $B_{\alpha}$.

We shall call, for brevity, a function radial if it depends on $r$ only. A simple consequence of our result is that there exist bounded radial quasiharmonic functions if and only if there exist bounded quasiharmonic functions.

We expect that our approach is extendable to other classes of quasiharmonic and biharmonic functions as well, and to other Riemannian manifolds which are invariant under rotation. In particular, there exist negative radial quasiharmonic functions on every $B_{\alpha}$.

2. The proof of our main result will be divided into Lemmas 1-6. We start by formulating the equation:

Lemma 1. A function $s(r)$ satisfies

$$
\Delta s=1
$$

on $B_{\alpha}$ if and only if

$$
s^{\prime \prime}+\left(\frac{N-1}{r}-\frac{2(N-2) \alpha r}{1-r^{2}}\right) s^{\prime}+\left(1-r^{2}\right)^{2 \alpha}=0 .
$$


Proof. The metric tensor $\left(g_{i j}\right)$ is diagonal, with elements

$$
\lambda^{2}, \lambda^{2} r^{2}, \lambda^{2} r^{2} \varphi_{1}, \cdots, \lambda^{2} r^{2} \varphi_{N-2},
$$

where $\varphi_{1}, \cdots, \varphi_{N-2}$ are functions of the coordinate angles $\theta^{1}, \cdots, \theta^{N-1}$. We set $\varphi=\left(\varphi_{1} \cdots \varphi_{N-2}\right)^{1 / 2}$, and have $\sqrt{g}=\lambda^{N} r^{N-1} \varphi, g^{r r}=\lambda^{-2}$, and

$$
\begin{aligned}
\Delta s & =-\frac{1}{\sqrt{g}} \frac{\partial}{\partial r}\left(\sqrt{g} g^{r r} s^{\prime}\right) \\
& =-\lambda^{-2}\left[s^{\prime \prime}+\left(\frac{N-1}{r}+\frac{(N-2) \lambda^{\prime}}{\lambda}\right) s^{\prime}\right],
\end{aligned}
$$

hence the lemma.

For convenience in later calculation, we rewrite (4) in the form:

$$
\begin{aligned}
& r^{2}\left(1-r^{2}\right) s^{\prime \prime}+r\left[(N-1)\left(1-r^{2}\right)\right. \\
& \left.\quad-2(N-2) \alpha r^{2}\right] s^{\prime}+r^{2}\left(1-r^{2}\right)^{2 \alpha+1}=0 .
\end{aligned}
$$

3. We are ready to give the function $s(r)$ referred to in the introduction. Here and later $\sum_{m}^{n}$ with $n<m$ will mean 0 .

LEMMA 2. Equation (3) is satisfied by the function

$$
s(r)=-\sum_{i=0}^{\infty} b_{i} r^{2 i+2},
$$

where

$$
b_{0}=\frac{1}{2 N}
$$

and for $i>0$,

$$
b_{i}=\frac{1}{2 N} \prod_{j=1}^{i} p_{j}+\sum_{j=1}^{i-1} q_{j} \prod_{k=j+1}^{i} p_{k}+q_{i}
$$

with

$$
\begin{gathered}
p_{i}=\frac{2 i[2 i+(N-2)(2 \alpha+1)]}{(2 i+2)(2 i+N)}, \\
q_{i}=\frac{\prod_{j=1}^{i}(j-2 \alpha-2) j^{-1}}{(2 i+2)(2 i+N)} .
\end{gathered}
$$

Proof. Substitution of (5) into (4') gives

$$
\begin{aligned}
& -\sum_{i=0}^{\infty}\left(1-r^{2}\right)(2 i+2)(2 i+1) b_{i} r^{2 i+2}-\sum_{i=0}^{\infty}(N-1)(2 i+2) b_{i} r^{2 i+2} \\
& +\sum_{i=0}^{\infty}[(N-1)+2(N-2) \alpha](2 i+2) b_{i} r^{2 i+4}+r^{2} \\
& \quad+r^{2} \sum_{i=1}^{\infty}\left(\prod_{j=1}^{i} \frac{j-2 \alpha-2}{j}\right) r^{2 i}=0 .
\end{aligned}
$$


On changing by unity the summation index in the coefficients of $r^{2 i+4}$ we obtain

$$
\begin{aligned}
& \sum_{i=0}^{\infty}(2 i+2)(2 i+N) b_{i} r^{2 i+2}=\sum_{i=1}^{\infty} 2 i[2 i+(N-2)(2 \alpha+1)] b_{i-1} r^{2 i+2} \\
& \quad+r^{2}+\sum_{i=1}^{\infty}\left(\sum_{j=1}^{i} \frac{j-2 \alpha-2}{j}\right) r^{2 i+2}=0 .
\end{aligned}
$$

We equate the coefficient of $r^{2}$ to 0 and have (6). The coefficient of $r^{2+2 i}$ for $i>0$ gives in notation (8), (9)

$$
b_{i}=p_{i} b_{i-1}+q_{i},
$$

which by induction yields (7).

4. We recall that we are only interested in $\alpha \in(-1,1 /(N-2))$, and we shall at this point introduce the condition $\alpha<1 /(N-2)$. To estimate $b_{i}$ given by (7), we start with $\Pi p_{j}$. Let $i_{0}$ be any integer such that

$$
i_{0} \geqq 1-\alpha(N-2)-\frac{N}{2}
$$

Further conditions on $i_{0}$ will be imposed in the course of our reasoning.

Lemma 3. For $\alpha<1 /(N-2)$ and $i>i_{0}$,

$$
\prod_{j=i_{0}+1}^{i} p_{j}<\frac{i_{0}+1}{i+1}\left(\frac{2 i_{0}+N+2}{2 i+N+2}\right)^{1-\alpha(N-2)} .
$$

Proof. In $p_{i}$, consider first the factor

$$
\delta_{i}=\frac{2 i+(N-2)(2 \alpha+1)}{2 i+N}=1-\frac{2[1-\alpha(N-2)]}{2 i+N} .
$$

For $\alpha<1 /(N-2)$ and $i>i_{0}$, we have $0<\delta_{i}<1$ and

$$
\log \delta_{i}<-\frac{2[1-\alpha(N-2)]}{2 i+N}<0 .
$$

Therefore

$$
\log \prod_{j=i_{0}+1}^{i} \delta_{j}<-2[1-\alpha(N-2)] \int_{i_{0}+1}^{i+1} \frac{d x}{2 x+N}
$$

and

$$
\prod_{j=i_{0}+1}^{i} \delta_{j}<\left(\frac{2 i_{0}+N+2}{2 i+N+2}\right)^{1-\alpha(N-2)} .
$$


In view of

$$
p_{i}=\frac{i}{i+1} \delta_{i}
$$

the lemma follows.

5. To proceed with the estimation of $b_{i}$ we now utilize also the condition $\alpha>-1$ and impose on $i_{0}$ the additional requirement

$$
i_{0} \geqq 2(\alpha+1) \text {. }
$$

In the sequel $c$ will stand for a positive constant, not always the same.

Lemma 4. For $\alpha \in(-1,1 /(N-2))$ and $i>i_{0}$,

$$
\left|q_{i}\right|<\frac{c}{(2 i+2)(2 i+N)}\left(\frac{i_{0}+1}{i+1}\right)^{2(\alpha+1)} .
$$

Proof. For $j>i_{0}$

$$
0<1-\frac{2(\alpha+1)}{j}<1
$$

and therefore

$$
\log \prod_{j=i_{0}+1}^{i}\left(1-\frac{2(\alpha+1)}{j}\right)<-2(\alpha+1) \sum_{i_{0}+1}^{i} \frac{1}{j}<-2(\alpha+1) \int_{i_{0}+1}^{i+1} \frac{d x}{x} .
$$

This gives

$$
\prod_{j=i_{0}+1}^{i} \frac{j-2 \alpha-2}{j}<\left(\frac{i_{0}+1}{i+1}\right)^{2(\alpha+1)}
$$

hence (14).

6. We now come to the main step in estimating $b_{i}$. It will be necessary to consider separately the cases $\alpha \in(-1 / N, 1 /(N-2)), \alpha=$ $-1 / 2$, and $\alpha \in(-1,0)-\{-1 / 2\}$.

Lemma 5. For $\alpha \in(-1 / N, 1 /(N-2))$, and $i>i_{0}$,

$$
\left|b_{i}\right|<c\left(\frac{1}{i}\right)^{2-\alpha(N-2)}+d\left(\frac{1}{i}\right)^{(3 / 2)-(1 / 2) \alpha(N-2)}+e\left(\frac{1}{i}\right)^{2(\alpha+2)},
$$

where $c, d, e$ are positive constants. 
Proof. By (7)

$$
b_{i}=b_{i_{0}} \prod_{j=i_{0}+1}^{i} p_{j}+\sum_{j=i_{0}+1}^{i-1} q_{j} \prod_{k=j+1}^{i} p_{k}+q_{i},
$$

and by (12)

$$
\left|b_{i_{0}} \prod_{j=i_{0}+1}^{i} p_{j}\right|<\frac{c}{i+1}\left(\frac{1}{2 i+N+2}\right)^{1-\alpha(N-2)}<c\left(\frac{1}{i}\right)^{2-\alpha(N-2)} .
$$

In view of (12) and (14) we have

$$
\begin{aligned}
\left|q_{j} \prod_{k=j+1}^{i} p_{k}\right|< & \frac{c}{(2 j+2)(2 j+N)}\left(\frac{1}{j+1}\right)^{2(\alpha+1)} \\
& \cdot \frac{j+1}{i+1}\left(\frac{2 j+N+2}{2 i+N+2}\right)^{1-\alpha(N-2)} .
\end{aligned}
$$

For $\alpha \in(-1 / N, 1 /(N-2))$,

$$
1-\alpha(N-2)<2(1+\alpha) \text {. }
$$

We therefore may and do require of $i_{0}$ further that for $j>i_{0}$

$$
\frac{(2 j+N+2)^{1-\alpha(N-2)}}{(j+1)^{2(1+\alpha)}}<2^{1-\alpha(N-2)} .
$$

We obtain

$$
\left|\sum_{j=i_{0}+1}^{i-1} q_{j} \prod_{k=j+1}^{i} p_{k}\right|<\frac{c}{2 i+2}\left(\frac{1}{2 i+N+2}\right)^{1-\alpha(N-2)} \sum_{j=i_{0}+1}^{i-1} \frac{1}{2 j+N}
$$

where

$$
\sum_{j=i_{0}+1}^{i-1} \frac{1}{2 j+N}<\int_{i_{0}}^{i-1} \frac{d x}{2 x+N}=\frac{1}{2} \log \frac{2 i+N-2}{2 i_{0}+N} .
$$

Accordingly, we set on $i_{0}$ the additional condition that for $i>i_{0}$

$$
\left(\frac{1}{i}\right)^{(1 / 2)[1-\alpha(N-2)]} \log \frac{2 i+N+2}{2 i_{0}+N}<1 \text {. }
$$

Then

$$
\left|\sum_{j=i_{0}+1}^{i-1} q_{j} \prod_{k=j+1}^{i} p_{k}\right|<c\left(\frac{1}{i}\right)^{(3 / 2)-(1 / 2) \alpha(N-2)} .
$$

A bound for the last term in (16) is immediate by (14):

$$
\left|q_{i}\right|<c\left(\frac{1}{i}\right)^{2(\alpha+2)} .
$$

We combine (16), (17), (19), and (20), and obtain (15). 
7. We are ready to state:

Lemma 6. For $\alpha \in(-1,1 /(N-2))$, the function $s(r)$ of Lemma 2 is bounded quasiharmonic.

In fact, for $\alpha \in(-1 / N, 1 /(N-2))$, all three exponents in (15) are $>1$, and therefore

$$
|s(r)|=\left|\sum_{i=0}^{\infty} b_{i} r^{2 i+2}\right|<\sum_{i=0}^{\infty}\left|b_{i}\right|<\infty .
$$

The case $\alpha=-1 / 2$ is simple, as all $q_{i}=0$, and by (8)

$$
\left|b_{i}\right|=\left|b_{i_{0}}\right| \prod_{j=i_{0}+1}^{i} p_{j}<\left|b_{i_{0}}\right| \frac{\left(2 i_{0}+2\right)^{2}}{(2 i+2)(2 i+N)}<c\left(\frac{1}{i}\right)^{2},
$$

whence $\sum_{0}^{\infty}\left|b_{i}\right|<\infty$.

It remains to consider the case $\alpha \in(-1,0)-\{-1 / 2\}$. We obtain at once

$$
\begin{aligned}
p_{k} & <\frac{2 k(2 k+N-2)}{(2 k+2)(2 k+N)}, \\
\prod_{j+1}^{i} p_{k} & <\frac{(2 j+2)(2 j+N)}{(2 i+2)(2 i+N)},
\end{aligned}
$$

and by (14)

$$
\left|q_{j}\right|<\frac{c}{(2 j+2)(2 j+N)} \cdot\left(\frac{1}{j+1}\right)^{2(\alpha+1)}
$$

for $j>i_{0}$. Therefore

$$
\sum_{j=i_{0}+1}^{i-1}\left|q_{j} \prod_{k=j+1}^{i} p_{k}\right|<\frac{c}{(2 i+2)(2 i+N)} \int_{i_{0}}^{i-1} \frac{d x}{(x+1)^{2(\alpha+1)}},
$$

where the integral has the value

$$
\frac{1}{-2 \alpha-1}\left[i^{-2 \alpha-1}-\left(i_{0}+1\right)^{-2 \alpha-1}\right]
$$

since $\alpha \neq-1 / 2$. As a consequence

$$
\sum_{j=i_{0}+1}^{i-1}\left|q_{j} \prod_{k=j+1}^{i} p_{k}\right|<c\left(\frac{1}{i}\right)^{3+2 \alpha}+d\left(\frac{1}{i}\right)^{2} .
$$

Similarly

$$
\left|b_{i_{0}} \prod_{k=i_{0}+1}^{i} p_{k}\right|<c\left(\frac{1}{i}\right)^{2}
$$


and

$$
\left|q_{i}\right|<c\left(\frac{1}{i}\right)^{2 \alpha+4}
$$

Since all exponents in (22)-(24) are $>1$, it follows again by (16) and (21) that the function $s(r)$ is bounded.

8. We have established our result:

THEOREM. There exist bounded quasiharmonic functions on the Riemannian ball $B_{\alpha}$ if and only if the function $s(r)$ of Lemma 2 is bounded.

In fact, we know that there exist bounded quasiharmonic functions on $B_{\alpha}$ if and only if $\alpha \in(-1,1 /(N-2)$ ) (Sario-Wang [16]). This together with Lemma 6 gives the theorem.

A simple consequence is perhaps worth stating. Let $R$ be the family of radial functions, characterized by the dependence on $r$ only. Denote by $O_{Q B R}$ and $O_{Q B}$ the classes of Riemannian manifolds which do not carry bounded radial quasiharmonic functions, or bounded quasiharmonic functions, respectively, and set $B=\left\{\cup B_{\alpha} \mid \alpha \in \boldsymbol{R}\right\}$.

Corollary 1. $B \cap O_{Q B R}=B \cap O_{Q B}$.

That is, there exist bounded radial quasiharmonic functions on $B_{\alpha}$ if and only if there exist bounded quasiharmonic functions.

CoROLlary 2. $B \cap O_{Q N R} \neq \varnothing$.

For $\alpha \in(-1,1 /(N-2))$, we have $s-\sup _{B_{\alpha}}|s| \in Q N R$. For all $\alpha$, it is readily seen that the function

$$
-1-\int_{0}^{r} \int_{0}^{\sigma}\left(\frac{\rho}{\sigma}\right)^{N-1} \frac{\left(1-\rho^{2}\right)^{N \alpha}}{\left(1-\sigma^{2}\right)^{(N-2) \alpha}} d \rho d \sigma
$$

is radial, negative, and quasiharmonic.

\section{REFERENCES}

1. Y. K. Kwon, L. Sario and B. Walsh, Behavior of biharmonic functions on Wiener's and Royden's compactifications, Ann. Inst. Fourier (Grenoble), 21 (1971), 217-226.

2. M. Nakai, Dirichlet finite biharmonic functions on the plane with distorted metric, (to appear).

3. M. Nakai and L. Sario, Biharmonic classification of Riemannian manifolds, Bull. Amer. Math. Soc., 77 (1971), 432-436.

4. - Quasiharmonic classification of Riemannian manifolds, Proc. Amer. Math. Soc., 31 (1972), 165-169. 
5. - Dirichlet finite biharmonic functions with Dirichlet finite Laplacians, Math. Z., 122 (1971), 203-216.

6. - A property of biharmonic functions with Dirichlet finite Laplacians, Math. Scand., 29 (1971), 307-316.

7. — Existence of Dirichlet finite biharmonic functions, Ann. Acad. Sci. Fenn., (to appear).

8. ㄴ. Existence of bounded biharmonic functions, J. Reine Angew. Math., (to appear).

9. - Existence of bounded Dirichlet finite biharmonic functions, Ann. Acad. Sci. Fenn. A. I., 505 (1972), 1-12.

10. - Biharmonic functions on Riemannian manifolds, Continuum Mechanics and Related Problems of Analysis, Nauka, Moscow, (1972), 329-335.

11. H. O'Malla, Dirichlet finite biharmonic functions on the unit disk with distorted metrics, Proc. Amer. Math. Soc., 32 1972, 521-524.

12. L. Sario, Lectures on biharmonic and quasiharmonic functions on Riemannian manifolds, Duplicated lecture notes, 1969-70, University of California, Los Angeles.

13. L. Sario and C. Wang, The class of $(p, q)$-biharmonic functions, Pacific J. Math., 41 (1972), 799-808.

14. Counterexamples in the biharmonic classification of Riemannian 2-manifolds, (to appear).

15. - Generators of the space of bounded biharmonic functions, Math. Z., 127 (1972), 273-280.

16. - Quasiharmonic functions on the Poincare $N$-ball, Rend. Mat. (to appear).

17. - Existence of Dirichlet finite biharmonic functions on the Poincaré 3-ball, Pacific J. Math., (to appear).

18. L. Sario, C. Wang and M. Range, Biharmonic projection and decomposition, Ann. Acad. Sci. Fenn. A. I., 494 (1971), 1-14.

19. C. Wang and L. Sario, Polyharmonic classification of Riemannian manifolds, Kyoto Math. J., 12 (1972), 129-140.

Received April 18, 1972 and in revised form November 15, 1972. The work was sponsored by the U.S. Army Research Office-Durham, Grant DA-ARO-D-31-124-71-G181, University of California, Los Angeles.

UNIVERSity of CALIForNia, LoS ANGeles 


\section{PACIFIC JOURNAL OF MATHEMATICS}

\section{EDITORS}

D. Gilbarg and J. Milgram

Stanford University

Stanford, California 94305

\author{
R. A. Beaumont \\ University of Washington \\ Seattle, Washington 98105
}

J. DuGUNDJI

Department of Mathematics

University of Southern California

Los Angeles, California 90007

Richard ARENS

University of California

Los Angeles, California 90024

\section{ASSOCIATE EDITORS}
E. F. BECKENBACH
B. H. NeumanN
F. WOLF
K. YosHIDA

\section{SUPPORTING INSTITUTIONS}

UNIVERSITY OF BRITISH COLUMBIA

CALIFORNIA INSTITUTE OF TECHNOLOGY

UNIVERSITY OF CALIFORNIA

MONTANA STATE UNIVERSITY

UNIVERSITY OF NEVADA

NEW MEXICO STATE UNIVERSITY

OREGON STATE UNIVERSITY

UNIVERSITY OF OREGON

OSAKA UNIVERSITY

\author{
UNIVERSITY OF SOUTHERN CALIFORNIA \\ STANFORD UNIVERSITY \\ UNIVERSITY OF TOKYO \\ UNIVERSITY OF UTAH \\ WASHINGTON STATE UNIVERSITY \\ UNIVERSITY OF WASHINGTON
* * * *
AMERICAN MATHEMATICAL SOCIETY \\ NAVAL WEAPONS CENTER
}

The Supporting Institutions listed above contribute to the cost of publication of this Journal, but they are not owners or publishers and have no responsibility for its content or policies.

Mathematical papers intended for publication in the Pacific Journal of Mathematics should be in typed form or offset-reproduced, (not dittoed), double spaced with large margins. Underline Greek letters in red, German in green, and script in blue. The first paragraph or two must be capable of being used separately as a synopsis of the entire paper. The editorial "we" must not be used in the synopsis, and items of the bibliography should not be cited there unless absolutely necessary, in which case they must be identified by author and Journal, rather than by item number. Manuscripts, in duplicate if possible, may be sent to any one of the four editors. Please classify according to the scheme of Math. Rev. Index to Vol. 39. All other communications to the editors should be addressed to the managing editor, Richard Arens, University of California, Los Angeles, California, 90024.

50 reprints are provided free for each article; additional copies may be obtained at cost in multiples of 50 .

The Pacific Journal of Mathematics is issued monthly as of January 1966. Regular subscription rate: $\$ 48.00$ a year (6 Vols., 12 issues). Special rate: $\$ 24.00$ a year to individual members of supporting institutions.

Subscriptions, orders for back numbers, and changes of address should be sent to Pacific Journal of Mathematics, 103 Highland Boulevard, Berkeley, California, 94708.

PUBLISHED BY PACIFIC JOURNAL OF MATHEMATICS, A NON-PROFIT CORPORATION

Printed at Kokusai Bunken Insatsusha (International Academic Printing Co., Ltd.), 270, 3-chome Totsuka-cho, Shinjuku-ku, Tokyo 160, Japan. 


\section{Pacific Journal of Mathematics}

\section{Vol. 46, No. 2 December, 1973}

Christopher Allday, Rational Whitehead products and a spectral sequence of

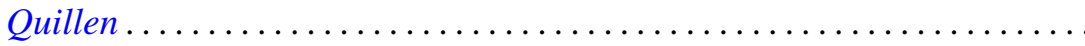

James Edward Arnold, Jr., Attaching Hurewicz fibrations with fiber

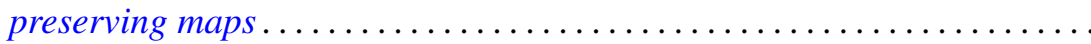

Catherine Bandle and Moshe Marcus, Radial averaging transformations with various metrics.................................

David Wilmot Barnette, A proof of the lower bound conjecture for convex

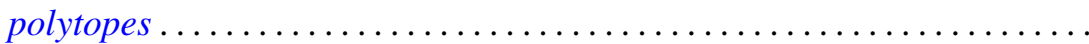

Louis Harvey Blake, Simple extensions of measures and the preservation of

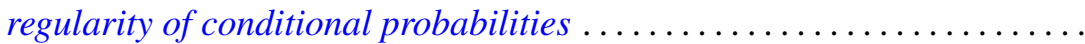

James W. Cannon, New proofs of Bing's approximation theorems for

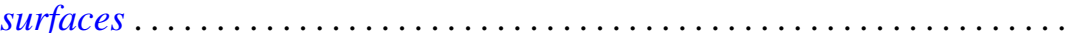

C. D. Feustel and Robert John Gregorac, On realizing HNN groups in

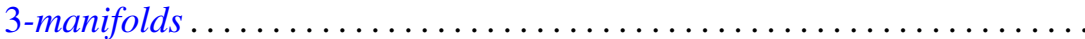

Theodore William Gamelin, Iversen's theorem and fiber algebras . . . . . . . . 389

Daniel H. Gottlieb, The total space of universal fibrations . . . . . . . . . . . .

Yoshimitsu Hasegawa, Integrability theorems for power series expansions of

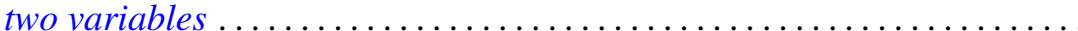

Dean Robert Hickerson, Length of period simple continued fraction expansion of $\sqrt{ } d$

Herbert Meyer Kamowitz, The spectra of endomorphisms of the disc algebra.

Dong S. Kim, Boundedly holomorphic convex domains

Daniel Ralph Lewis, Integral operators on $\mathscr{L}_{p}$-spaces ...

John Eldon Mack, Fields of topological spaces . . . . . . . . .

V. B. Moscatelli, On a problem of completion in bornology

Ellen Elizabeth Reed, Proximity convergence structures. .

Ronald C. Rosier, Dual spaces of certain vector sequence spaces .

Robert A. Rubin, Absolutely torsion-free rings

Leo Sario and Cecilia Wang, Radial quasiharmonic functions . .

James Henry Schmerl, Peano models with many generic classes .

H. J. Schmidt, The $\mathscr{F}$-depth of an $\mathscr{F}$-projector ............

Edward Silverman, Strong quasi-convexity. . . . . . . . . . . . . . . . . 549

Barry Simon, Uniform crossnorms ....................... 555

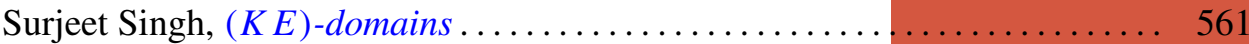

Ted Joe Suffridge, Starlike and convex maps in Banach spaces . . . . . . . . 575

Milton Don Ulmer, $C$-embedded $\Sigma$-spaces . . . . . . . . . . . . . . . . 591

Wolmer Vasconcelos, Conductor, projectivity and injectivity . . . . . . . . . 603 